\title{
Åsa Berggren
}

Med kärret som källa:

Om begreppen offer och ritual inom arkeologin

Vägar till Midgård, 13

Lund: Nordic Academic Press 2010

400 pages, including an 11 page English summary

ISBN 978-91-89116-98-6

Review by Fredrik Fahlander

Åsa Berggren's doctoral thesis, Med kärret som källa, is a critical discussion on ritual, sacrifice, and ritualised practice in relation to a recently excavated fen, Hindebygården, located in the Swedish province of Scania. It is, as Berggren states in the introduction, an attempt 'to try out practice theory as a tool for studying wetland depositions in terms of embodiment and objectification' (p. I6). Although the case study covers more or less the last half of the book, the main focus is on concepts, perspectives, theoretical points of departure and their consequences. This is elaborated in the first half of the thesis, a quite thorough theoretical and methodological section divided into two chapters. The first of these chapters (chapter 2) deals with questions of ritual and sacrifice, and points to some problems with certain perspectives and terminology. Here Berggren advocates the approach developed by Catherine Bell (1992) whereby ritual is understood in terms of 'strategic ritualization', focusing on practice before meaning in rituals. This change in perspectives, Berggren admits, may not necessarily lead to radically different interpretations of wetland deposits, but rather opens up the discussion and steers it away from the traditional ethnographical stereotypes and generalisations. 
In the subsequent chapter (3), Berggren, following Bell, promotes the sociology of Pierre Bourdieu and practice theory as her main theoretical point of departure. It is a logical choice but perhaps a less subject-oriented perspective, or even a symmetrical perspective could have suited the nature of the data even better. Berggren, however, does 'enhance' Bourdieu's theory by also emphasising the embodied and sensuous aspects of social practice. Archaeology has by tradition focused on sight as the primary sense among both past people and archaeologists. Here, Berggren makes a great effort in highlighting suitable examples and giving convincing arguments for the importance of, for example, smell, sound, touch and even 'sense of ritual'. The multi-sensuous approach then runs through the whole case study, emphasising how alterations in sounds, colours and general appearance over time affect the experience of the fen and the practices performed there.

The two chapters $(2 \& 3)$ cover about a third of the volume (I 40 pages) and encompass an in-depth discussion of the facets of ritual, embodiment and social practice, and here and there the subject of the thesis, the wetland depositions, tends to fall out of focus. The wide scope may, however, be justified by the fact that Berggren discusses issues not known to all readers (i.e. archaeology of the senses and emotion), and it is, of course, possible for readers familiar with this research to simply skip these two chapters and go straight to the case study and discussion (chapters $4 \& 5$ ).

The case study, Hindbygården fen, is a truly fascinating site with great potential. The fen has been in use for depositions and activities from the Late Mesolithic (c. $4500 \mathrm{BC}$ ) until present day, although the main focus in the thesis ends with the Early Bronze Age around I Ioo BC. The wetland has been subject to a full-scale excavation including exhaustive botanical analyses, and it offers a suitable case to discuss not only ritual and deposition but also changes in social structure over time, problems of representativity, and questions of time and sequence. The range of different things that have been put down, laid out, or thrown into the wetland covers a great number of different materialities such as elaborated stone axes, human and animal bone, fossil sea urchins, pots and sherds, flint daggers and sickles, a bronze axe - not to mention the over Io tonnes of stone (!). There are also traces of constructions and features such as rows of sticks, posts, cooking pits, an oak footbridge, hearths, crushed pots, and a few burials adjacent to the wetland.

Berggren makes a systematic, almost narrative, interpretation of the fen divided into four main phases (Late Mesolithic, Early Neolithic, Middle Neolithic and Late Neolitic/Early Bronze Age). Each section begins with a description of the wetland, its changing flora and fauna, 
followed by an interpretation of the 'affordances' of the fen and how it might been experienced from the 'outside' and from 'within', respectively. Here, Berggren does a great job in seamlessly including the multisensuous aspects of sound, touch and smell in her interpretations of the performed practices. Each period is illustrated with suggestive drawings by Hans Ekerow. Distribution maps are, however, by and large omitted and the reader is referred to a previously published report (Berggren 2007). This is a bit unfortunate; such illustrations would greatly improve the understanding of the descriptions. The same goes for details concerning carbon determinations and some other hard data. Such tables and illustrations could easily have been accommodated in an appendix in order not to clutter the text.

The choice to organize the activities around the fen according to traditional archaeological time periods is understandable considering that many of the artefacts are dated by type. However, as such they tend to act like small boxes in which things either fit or do not and thus become both the medium and result. Berggren recognises the problematic and does indeed emphasise social heterogeneity and social differentiation, but her local interpretations are nonetheless often hampered by the general image of each period. The particularities of the site tend to be understood through the prism of the general and regional rather than vice versa. For instance, instead of interpreting the fen as a site for 'local commoners' (p. 357), the same arguments could as well be used to criticise the dominant idea of 'increased stratification'. The ideal would perhaps be if the temporal scale could be divided by the type and frequency of action taking place at the wetland, providing both long and short term at the same time. Such a perspective would allow a complex site like the Hindbygården fen to have a greater effect on, or to broaden, the general image of the past.

In sum, Med kärret som källa is a thorough and original text that inspires further questions and discussions beyond the aims of the thesis. It is a bit unfortunate that the thesis is not accessible to readers outside the Scandinavian-language sphere. Both the fascinating material of the fen and the innovative multi-sensuous approach to ritualised practice are indeed worthy a greater audience.

\section{References}

Bell, C. 1992. Ritual Theory, Ritual Practice. Oxford: Oxford University Press.

Berggren, Å. 2007. Till och från ett kärr. Den arkeologiska undersökningen av Hindbygarden [To and From a Fen. The Archaeological Investigation of Hindbygården]. Malmöfynd I7. Malmö: Malmö Kulturmiljö. 